\title{
Detecção de exsudações de hidrocarbonetos por geobotânica e sensoriamento remoto multi-temporal: estudo de caso no Remanso do Fogo (MG)
}

\author{
Carlos Roberto de Souza Filho' ${ }^{1}$, Vagney Augusto ${ }^{2,3}$, Wilson José Oliveira ${ }^{4}$ \& Talita Lammoglia ${ }^{3}$
}

\begin{abstract}
Resumo Este trabalho contemplou a caracterização espectral da vegetação sobrejacente a uma porção da Bacia do São Francisco, na região conhecida como Remanso do Fogo (MG), particularmente em locais onde microexsudações foram previamente reconhecidas por geoquímica. O objetivo foi relacionar áreas ricas em hidrocarbonetos gasosos a possíveis anomalias geobotânicas. O estudo foi realizado a partir do processamento de imagens multiespectrais e multi-temporais do sensor ASTER/TERRA, bem como por análises gasométricas de hidrocarbonetos em solo. O processamento dos dados envolveu: (i) a avaliação estatística dos dados de geoquímica; (ii) a caracterização espectral da vegetação nas áreas com anomalias geoquímicas de gás, em conjunto com pontos já conhecidos de ocorrências de exsudações gasosas; (iii) a aplicação de técnicas de classificação espectral as imagens ASTER (ângulo espectral n-dimensional; desmistura espectral parcial multi-criterial) objetivando separar áreas com ocorrências de exsudações de HCs com base em espectros característicos identificados. A análise espectral dos pixels nas áreas anômalas possibilitou a sua diferenciação de áreas não afetadas pelas microexsudações. A partir dos espectros de referência identificados como anômalos, observou-se modificações marcantes na reflectância da vegetação nas bandas 2 (0.63-0.69 $\mu \mathrm{m}), 3$ (0.76-0.86 $\mu \mathrm{m}), 4(1.60-1.70 \mu \mathrm{m})$ e $6(2.185-2.225 \mu \mathrm{m})$ do ASTER, demonstrativas da associação espacial entre anomalias geoquímicas e geobotânicas. Ademais, áreas detectadas remotamente como espectralmente anômalas foram verificadas no campo e mostraram evidências de exsudação na sua maioria, demonstrando a adequação do modelo de detecção. A abordagem metodológica aqui introduzida nesse estudo de caso representativo revela seu grande potencial para a detecção e caracterização de exsudações, as quais constituem importantes indícios para ocorrência de recursos de óleo e gás.
\end{abstract}

Palavras-chave: exsudação de hidrocarbonetos, ASTER, geobotânica, análise espectral.

\begin{abstract}
Hydrocarbon Seepage Detection through Geobotanic and Multi-temporal Remote Sensing: A Case Study on Remanso do Fogo (MG). This work focus on the spectral characterization of a set of vegetation comprised in the Sao Francisco Basin, particularly in an area known as Remanso do Fogo (Minas Gerais State), where seepages have already been detected visually and by geochemistry. The main objective was to evaluate the likely correlation between areas rich in hydrocarbons and geobotanical anomalies. The investigation was based on multitemporal and multispectral ASTER images and gasometrical data. The processing included: (i) statistical evaluation of gasometrical data, (ii) spectral characterization of vegetation in tracts inside and outside hydrocarbon geochemical anomalies, and (iii) ASTER imagery spectral classification using n-dimensional spectral angle and multi-criteria partial spectral unmixing methods, which were applied with the ultimate purpose of remote detection of areas with hydrocarbon seepages, mainly guided by vegetation spectra. Spectral analysis of image pixels in areas with known HC anomalies make it possible to distinguish areas affected or not by HCs seeps. Vegetation spectra collected within HC anomalies indicate key signatures in ASTER bands $2(0.63-0.69 \mu \mathrm{m}), 3(0.76-0.86 \mu \mathrm{m}), 4(1.60-1.70 \mu \mathrm{m})$ and $6(2.18-2.22 \mu \mathrm{m})$, strengthening the spatial association of geochemical and geobotanical anomalies. Furthermore, areas mapped remotely as spectrally anomalous showed evidences of seeps in numerous sites verified in the field, proving the efficiency of the detecting model. The research strategy here introduced in a unique case study reveals its vast potential for detection and characterization of seepages, which are important vectors for of oil and gas resources.
\end{abstract}

Keywords: hydrocarbon microseepage, ASTER, geobotany, spectral analysis.

INTRODUÇÃO Exsudações de hidrocarbonetos (HCs) são processos documentados em várias partes do mundo, nas formas líquida e gasosa, em ambientes marinhos ou continentais (Jones \& Drozd 1983). Estes eventos, também conhecidos como seepages, têm um papel respeitável na exploração de novas bacias

1 - Instituto de Geociências, Universidade Estadual de Campinas, Campinas (SP), Brasil. E-mail: beto@ige.unicamp.br

2 - Depto. Desenvolvimento de Projetos Minerais (DIPM), VALE, Rio de Janeiro (RJ), Brasil. Email: vagney.augusto@cvrd.com.br

3 - Programa de Pós-Graduação, Universidade Estadual de Campinas, Campinas (SP), Brasil. E-mail: talita.lammoglia@ige.unicamp.br

4 - PETROBRAS, ENGENHARIA/IETEG/ETEG/EAMB, Rio de Janeiro (RJ), Brasil. E-mail: wilsonjo@petrobras.com.br 
petrolíferas, uma vez que são evidências da presença de HCs em sub-superficie (Hunt 1996). Seepages ocorrem na presença de caminhos permeáveis que possam conduzir escapes de HCs da rocha fonte ou reservatórios para a superfície. Estes caminhos incluem poros de rochas, inconformidades estratigráficas, reservatórios rompidos, intrusões de domos salinos (Link 1952), falhas, juntas e acamamentos na forma de uma rede de espaços vazios interconectados (Thompsom et al. 1994). Os HCs podem também migrar na forma de bolhas associadas a águas subterrâneas (colóides), movimentando-se com velocidade da ordem de $\mathrm{mm} / \mathrm{s}$. Os HCs leves $\left(\mathrm{C}_{1}-\mathrm{C}_{5}\right.$ - metano, etano, propano, butano e pentano) migram para superfície na forma de gás, formando os microseepages, enquanto HCs mais pesados $\left(>\mathrm{C}_{5}\right)$ migram na fase líquida, formando os macroseepages. A migração de HCs para superfície provoca uma série de alterações diagenéticas nos estratos sobrejacentes aos depósitos.

O uso de dados multiespectrais e hiperespectrais para estudos de alterações no sistema solo-vegetação causadas por microexsudações de HCs foi abordado em detalhe por poucos autores, entre os quais se destacam Yang Hong, et al. (2000), Almeida Filho (2001, 2002), Van der Meer (2002) e Noomen et al. (2007). Dados multiespectrais obtidos por sensores orbitais como o Landsat TM têm sido bastante utilizados para este fim, porém sua baixa resolução espectral limita a caracterização dos efeitos diretos e indiretos das microexsudações na cobertura. Com advento do sensor ASTER, uma nova janela de oportunidades foi aberta para esse tipo de estudos. Embora dados ASTER sejam utilizados para fins multidisciplinares, poucas investigações foram até hoje realizadas para a caracterização espectral de áreas afetadas por microexsudações baseadas nesses dados. Dentre os trabalhos já publicados (e.g., Fu et al. 2007, Lammoglia et al. 2007, Augusto et al. 2005), desconhece-se pesquisa centrada em dados ASTER e geobotânica para detecção de exsudações, tal como aqui objetivado.

Neste contexto, este trabalho visa à caracterização espectral da vegetação sobrejacente a uma porção da Bacia do São Francisco, particularmente em locais onde fenômenos de microexsudações foram previamente reconhecidos por geoquímica, buscando relacionar áreas ricas em HCs às possíveis anomalias geobotânicas. O estudo foi realizado a partir do processamento de imagens multiespectrais, temporais do sensor ASTER/ TERRA e dados geoquímicos de HCs. Os resultados foram validados por observações de campo.

\section{Alterações superficiais induzidas por hidrocarbone- tos e deteç̧ão por sensoriamento remoto Pesquisas indicam que HCs (metano, propano, etano e pentano) em superfície ou próximo a ela podem trazer mudan- ças significativas nos valores de $\mathrm{pH}$ e Eh do ambiente, influenciando na estabilidade de minerais, velocidade das reações e elementos químicos. Nesse ambiente, anomalias redutoras locais podem ser constituídas, fa- vorecendo o desenvolvimento de mudanças químicas e mineralógicas, afetando solos, rochas e a vegetação (Schumacher 1996) (Figs. 1, 2 e 3), muitas das quais}

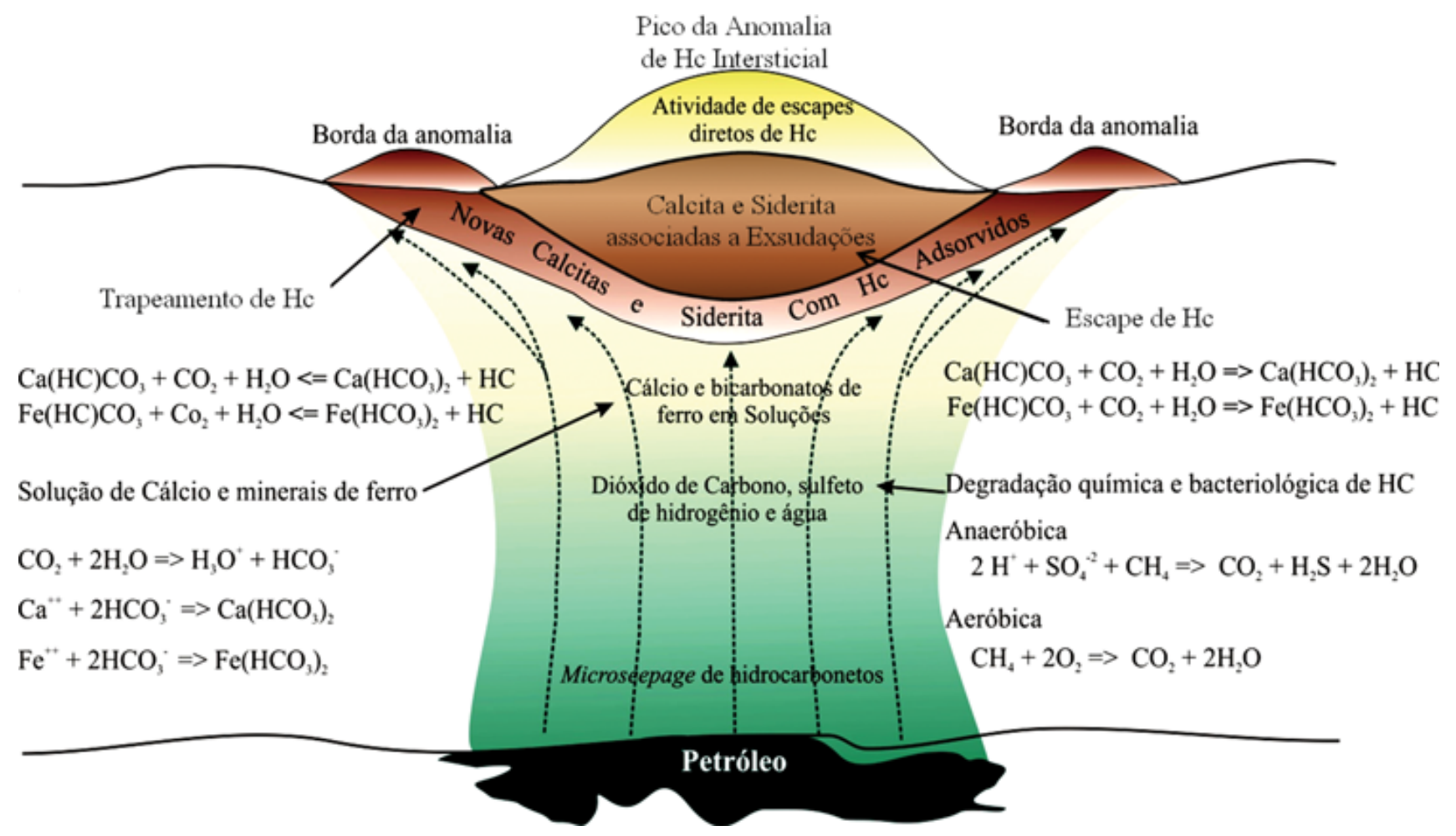

Figura 1 - Modelo de alterações superficiais associadas à micro-seepages (modificado de Saunders et al. 1999). 


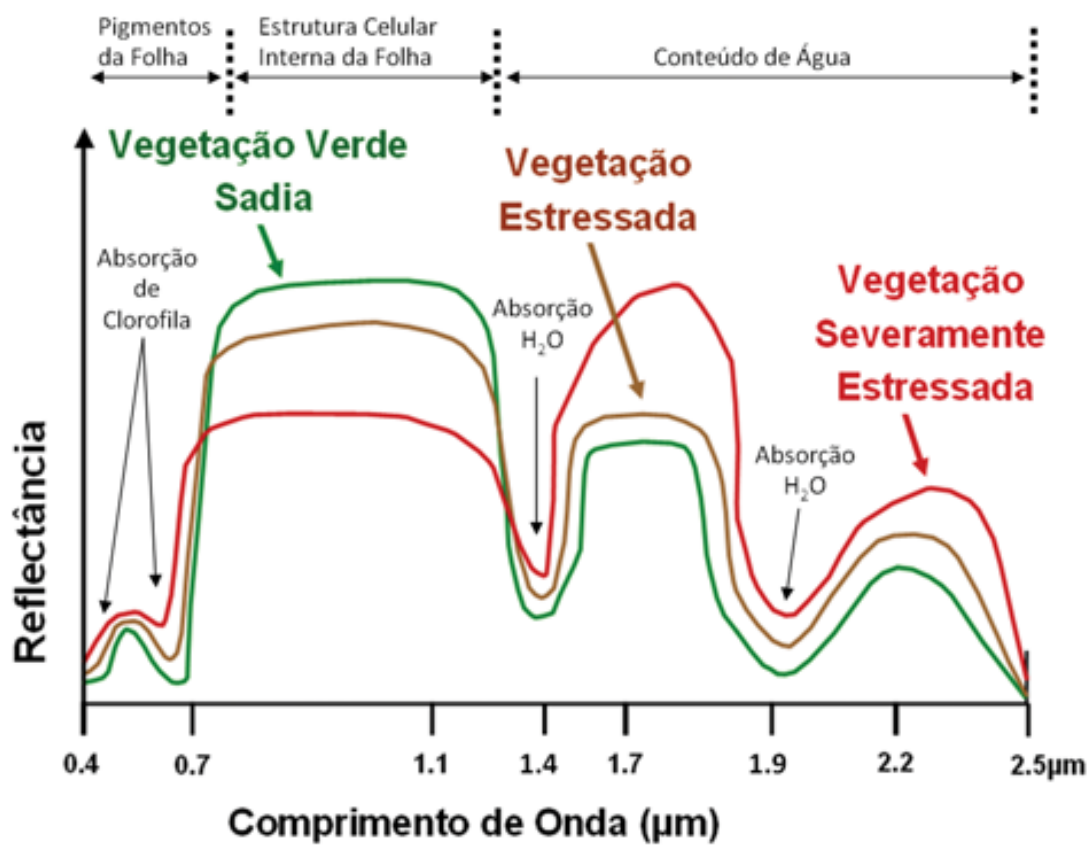

Figura 2 - Comparação das curvas espectrais da vegetação sadia e estressada (diagrama esquemático).

podem ser detectadas por sensoriamento remoto.

ANOMALIAS GEOBOTÂNICAS Estudos das interações solo-vegetação em locais com exsudação demonstram que HCs são tóxicos para plantas somente em concentrações muito altas, embora em baixas concentrações os efeitos indiretos causados por HCs na degradação das plantas sejam bastante evidentes. Diversos fatores podem afetar a vegetação: (i) a principal causa de alterações deve-se a escassez de oxigênio (Pirone 1960) causada pela degradação de HCs (oxidação) e oxidação metanotrófica de $\mathrm{CH}_{4}$ (Etiope \& Klusman 2002), (ii) a redução bacteriológica de oxigênio é acompanhada por aumento do dióxido de carbono $\left(\mathrm{CO}_{2}\right)$ em concentrações de 5\% - 15\% (Hoeks 1972), o qual pode causar morte da vegetação pela interrupção da respiração da raiz e acidificação da água subterrânea (Macek et al. 2005, Bergfeld et al. 2006), (iii) a baixa quantidade de oxigênio e aumento de $\mathrm{CO}_{2}$ e ácidos orgânicos podem afetar o $\mathrm{pH}$ e o Eh dos solos, modificando a solubilidade de elementos traços e, conseqüentemente, a disponibilidade destes para as plantas, (iv) a diminuição da porosidade dos solos devido à cimentação carbonática pode afetar as plantas (Flower et al. 1981, apud Oliveira 1998).

Os principais efeitos nas plantas em solos ricos em HCs são: crescimento debilitado, mudança nas estruturas das folhas (acompanhada de degradação das clorofilas, resultando variação da coloração), quedas de folhas e menor densidade de plantas (que, em geral, aparecem atrofiadas); em casos extremos, pode ocorrer a morte da vegetação (Oliveira 1998, Smith et al., 2004). Plantas cultivadas em condições de escassez de oxigênio mostram decréscimo de fotossíntese após 8 dias e decréscimo do conteúdo de clorofila entre 20 40\% após 11 dias (Huang et al., 1997, Noomen 2007).
As deficiências minerais afetam primeiro o teor de clorofila e, em seguida, a estrutura anatômica, sendo comum a incidência de clorose por carência de Ferro. A toxidade química pode produzir senescência precoce e rebrota tardia; clorose; toxicidade sazonal; variação na estrutura da cobertura vegetal; gigantismo e nanismo.

A resposta espectral da vegetação verde é muito característica (Fig. 2), pouco variando de espécie para espécie (Meneses et al. 2001). Na região do visível (VIS: 0,4 a $0,7 \mu \mathrm{m}$ ), de domínio dos pigmentos foliares, a reflectância das plantas é genericamente baixa (5-15\%); as feições de absorção ocorrem devido à presença de pigmentos fotossintéticos como clorofilas ('a' e 'b') e carotenóides (que compõem o ciclo da xantofila - pigmento amarelo), além de outros pigmentos como a antocianina, que é dependente do $\mathrm{pH}$ (cor-de-rosa, púrpura ou vermelho). Os carotenóides são mais abundantes na fase de senescência da planta, enquanto as antocianinas ocorrem em praticamente todas as fases, da juventude a senescência. A região do infravermelho próximo (NIR: 0,7-1,3 $\mu \mathrm{m}$ ) é aquela onde os pigmentos foliares são transparentes. No NIR: (i) a radiação eletromagnética é refletida ou transmitida e a absorção é mínima $(<10 \%)$; (ii) a água infrafoliar não produz bandas de absorção intensa; (iii) a $\sim 0,7 \mu \mathrm{m}$, a reflectância passa de $5 \%$ a $>50 \%$ na zona conhecida como borda vermelha (ou red edge); (iv) nas folhas delgadas e compactas, a trasmitância é maior que a reflectância, ao passo que nas folhas espessas a reflectância é muito maior que a transmitância; (v) folhas secas (sem pigmento e água) têm reflectância de $\sim 80 \%$ nessa faixa. (vi) as variações de reflectância nessa região são controladas pela estrutura anatômica da folha. A região do infra-vermelho de ondas curtas (SWIR - 1,3-2,5 $\mu \mathrm{m}$ ) é marcada por feições relacionadas ao domínio da água 
na estrutura foliar da planta, com bandas de absorção centradas em $1,45 \mu \mathrm{m}$ e $1,95 \mu \mathrm{m}$ e a partir de $2,5 \mu \mathrm{m}$, alternados a máximos de reflectância, centrados em1,65 $\mu \mathrm{m}$ e $2,2 \mu \mathrm{m}$. No SWIR ocorrem as feições de absorção dos compostos bioquímicos lignina, celulose, amido, proteínas, açúcares, cuja detecção é dificultada pela origem de suas feições de absorção: a ligação O-H.

As deficiências minerais somadas à toxidade química do solo causadas pela exsudação podem afetar o comportamento espectral da vegetação nas regiões do visível, infravermelho próximo e de ondas curtas. Embora a reflectância da vegetação esteja condicionada à forte absorção causada pela água no infravermelho de ondas curtas, Ripple (1986) verificou que folhas sob estresse hídrico apresentam reflectância maior no visível, menor no infravermelho próximo e maior no infravermelho de ondas curtas. Na literatura, é descrito também decréscimo na porcentagem da reflectância máxima no platô do infravermelho próximo, devido aos danos impostos à estrutura das folhas; aumento da reflectância no ponto de absorção máxima da clorofila devido à redução desse componente na planta; e mudança da posição do red edge na direção de comprimentos de onda mais curtos (blue shift) ou em direção de comprimentos de onda maiores (red shift) (Van der Meer et al. 2002). Noomen (2007) indica que, em experimentos controlados, baixas concentrações $(0,75 \%)$ de gás etano causam decréscimo da reflectância entre 550-750 nm, particularmente na região do amarelo $(560-700 \mathrm{~nm})$. Em experimentos com altas concentrações de etano (4 a 20\%) e escassez de oxigênio no solo, as mudanças na curva espectral são mais pronunciadas e devidas ao decréscimo do conteúdo de clorofila (Fig. 2).

A detecção das condições de estresse na vegetação pode ser monitorada pela redução da área foliar total exposta ao sensor (dossel). Essa redução pode surgir da perda direta de folhas, da mudança de sua orientação ou da interrupção de crescimento da planta. Nestes casos, a reflectância tende a ser alterada no infravermelho próximo, por causa da redução do mecanismo de camadas (soma da energia refletida das folhas inferiores e do topo) ou por um aumento da exposição do solo (Valeriano 2003). Em experimentos de campo, Noomen (2007) demonstrou que num raio de $10 \mathrm{~m}$ de distância da exsudação há domínio de solo nu na forma de halo circular, enquanto entre 20 e $30 \mathrm{~m}$ observa-se um anel com poucas espécies, feição espacial que pode ser utilizada para detecção remota dos vazamentos/exsudações. A autora demonstrou também que, em tese, exsudações podem ser detectadas por anomalias geobotânicas após duas semanas de vazamentos.

FORMAÇÃO DE CARBONATOS E ANOMALIAS GEOMORFOLÓGICAS Os carbonatos diagenéticos, na forma de cimento, são alterações mais comuns e associadas aos campos de petróleo (Fig. 3). Estes carbonatos são formados principalmente por oxidação do petróleo, particularmente a partir do metano, devido a reações tanto em ambientes aeróbicos como anaeróbicos (Schumacher 1996). Quando estas reações ocorrem, o dióxido de carbono reage com água para produzir bicarbonato. Este se associa com $\mathrm{Ca}$ e $\mathrm{Mg}$ em águas subterrâneas, precipitando o carbonato na forma de calcita ou dolomita, às vezes rica em Mn e MG, e carbonato rico em ferro (e.g. siderita). Tais processos geram endurecimento do solo (cimentação) e favorecem a formação de anomalias geomorfológicas (relevo elevado no local) (Thompson et al. 1994, Saunders et al. 1999). Os carbonatos podem ser remotamente detectados com base em suas feições diagnósticas no intervalo do SWIR (e.g 2,34 $\mu \mathrm{m}$ ).

\section{DESCOLORAÇÃO DE SOLOS AVERMELHADOS} (BLEACHING): também por ação de soluções ácidas, os íons férricos presentes na hematita, goetita e outros minerais limoníticos são alterados para íons ferrosos, resultando na perda da coloração avermelhada dos solos e rochas (bleaching) (e.g., Donovan 1979, 1986, Everett et al. 2002) (Fig. 3). Os possíveis agentes responsáveis pela geração de um ambiente redutor em áreas de exsudação são o $\mathrm{H}_{2} \mathrm{~S}$ e o $\mathrm{CO}_{2}$ ambos resultantes da degradação química e bacteriológica dos HCs. Este fenômeno pode ser detectado espectralmente pela mudança do comportamento espectral da rocha/solo na região do visível do EEM em função da perda do conteúdo de Fe férrico. Nesse caso, observa-se um decréscimo acentuado do gradiente de reflectância no visível, pois a hematita, goethita e limonita, que têm respostas espectrais decrescentes da radiação vermelha para a radiação azul, tendem a ser removidas.-

ALTERAÇÕES DE ARGILO-MINERAIS: o ambiente redutor e de condições ácidas promovem a alteração de feldspatos para argilas. Nesse ambiente, argilo-minerais, como ilita e esmectitas, podem ser convertidas para caulinitas, desenvolvendo zonas com concentrações anômalas desse mineral na área de exsudação (Schumacher 1996) (Fig. 3). Segel et al. (1986), no campo de Lisbom Valley, demonstraram a presença de caulinita em quantidades até cinco vezes superiores no centro da área anômala em relação a áreas mais distantes e inalteradas, dominadas por plagioclásio e micas. A caulinita $\left(\mathrm{Al}_{14}\left[\mathrm{SiO}_{10}\right](\mathrm{OH})_{8}\right)$ pode ser caracterizada espectralmente por suas duas duplas de feições de absorção diagnósticas na região do SWIR, em 1,40-1,42 $\mu \mathrm{m}$ e 2,162-2,206 $\mu \mathrm{m}$, além de feições de absorção acessórias em 2,312, 2,350 e 2,380 $\mu \mathrm{m}$.

OUTRAS ALTERAÇÕES Áreas portadoras de seepages têm sido associadas à presença de águas sulfurosas ou salinas, neo-mineralizações específicas e altos topográficos. Ademais, o ambiente redutor criado próximo à superfície pode levar a formação, mobilização e concentração de minerais radioativos e de óxidos e sulfetos magnéticos, tais como pirita e magnetita, sendo o último pseudomorfo de hematita e de sulfetos como pirrotita e greigita. Soluções ácidas também podem modificar o potássio para outros isótopos radioativos em argilominerais (ilita em solos), gerando anomalias de baixo potássio. O ambiente redutor provocado pelas bactérias também favorece a precipitação de minerais de urânio (e.g., ura- 

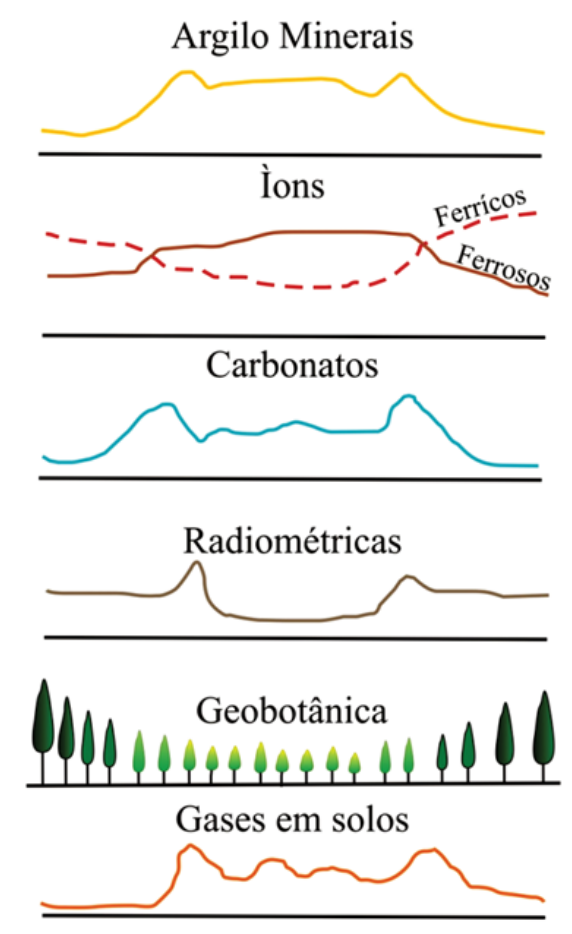

Figura 3 - Anomalias associadas às alterações superficiais resultantes $d a$ degradação dos HCs (modificado de Van der Werff \& Lucieer, 2004). ninita), antes instável no meio (Schumacher 1996) (Fig. $3)$.

\section{LOCALIZAÇÃO E ASPECTOS GEOLÓGICOS} DA ÁREA DE ESTUDO A área de estudo (Fig. 4) localiza-se próxima ao encontro dos rios São Francisco e Paracatu, nas imediações da localidade Cachoeira do Manteiga, Município de Buritizeiro (MG). A região de estudo é conhecida como Remanso do Fogo por apresentar numerosas emanações naturais de HCs. O Remanso do Fogo está contido na Bacia intracratônica do São Francisco, a qual é preenchida por unidades sedimentares mais jovens que $1.8 \mathrm{Ga}$, de complexa história geológica.

Na região de Remanso do Fogo afloram sedimentos do Grupo Bambuí, pertencentes ao Supergrupo São Francisco. A estratigrafia deste Supergrupo engloba duas unidades neoproterozóicas: o Grupo Macaúbas, na base, e o Grupo Bambuí, no topo. O Grupo Macaúbas compreende sedimentos glácio-continentais proximais e distais, compostos por uma associação de diamictitos, arenitos e pelitos. O Grupo Bambuí é composto pelas Formações Samburá (conglomerado, pelitos), Sete Lagoas (margas, calcilutitos, calcarenitos, biolititos), Serra de Santa Helena (pelitos), Lagoa do Jacaré (calcarenitos, pelitos), Serra da Saudade (pelitos) e Três Marias (pelitos, arenitos) (Alkmim \& Martins-Neto 2001).
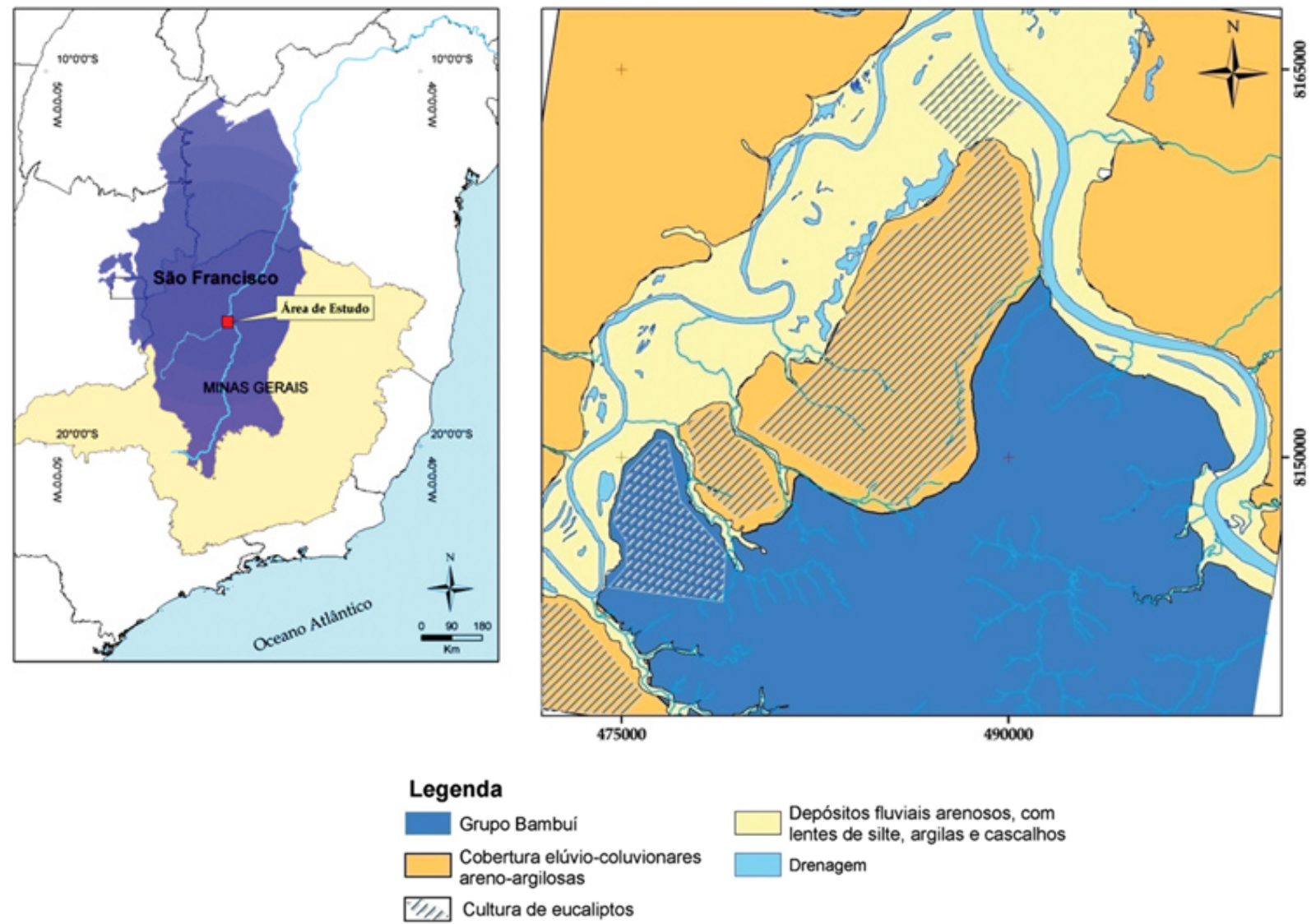

Figura 4 - Mapas regional e de detalhe da área de estudo. Mapa de localização regional (a) e mapa geológico simplificado (b) da região de Remanso do Fogo, Bacia do São Francisco. A área de estudo compreende a confluência dos rios Paracatu (esquerda) e São Francisco (direita). 
$\mathrm{Na}$ área de estudo, os sedimentos do Grupo Bambuí estão cobertos por depósitos fluviais arenosos, com lentes de silte, argila e cascalho (depósitos aluvionares), e depósitos elúvio-coluvionares areno-argilosos, com conglomerado em níveis basais. Localmente, os estratos do Grupo Bambuí apresentam-se suavemente dobrados, configurando sinclinais e anticlinais de grandes amplitudes. Evidências sísmicas de falhas indicam que as mesmas funcionaram como caminhos preferenciais de migração dos gases em direção a superfície, o que explica os seepages de HCs verificados na região (Oliveira 1998).

As rochas geradoras inseridas no Grupo Bambuí (i.e Formação Sete Lagoas e Lagoa do Jacaré) incluem folhelhos e siltitos pretos, ricos em matéria orgânica, além de calcários estromatolíticos (Pinto \& MartinsNeto 2001). Dois tipos de reservatórios foram definidos: carbonatos do Bambuí, em especial a Formação Sete Lagoas, e silicatos grosseiros do Grupo Macaúbas. Trabalhos publicados sugerem predominância de porosidade secundária, ou seja, reservatórios fraturados (Toledo et al. 1998).

\section{MATERIAIS E MÉTODOS}

Geoestatística Os dados geoquímicos utilizados nesse estudo foram derivados de análises de cromatografia gasosa em amostras de solos, coletadas durante um levantamento de superfície, executado pela equipe de exploração da Petrobrás, em 1987. Estas análises tiveram como objetivo identificar as concentrações superficiais de hidrocarbonetos (HC) gasosos leves como metano, etano, propano, butano, pentano e hexano $(\mathrm{C} 1, \mathrm{C} 2, \mathrm{C} 3$, C4, C5 e C6) para avaliação das ocorrências naturais de gases na região de Remanso do Fogo. Foram coletadas 566 amostras de solos, em profundidade de $1 \mathrm{~m}$, nas vias vicinais de fácil acesso, sendo restrita a estradas e carreadores ao longo das plantações de eucalipto na área de estudo (Oliveira 1998).

A análise dos dados geoquímicos teve como objetivo a separação de anomalias do padrão (background) regional para os diversos tipos de HCs mensurados, e conseqüente delimitação dos locais com maiores concentrações de exsudações na superfície. Estas foram definidas do seguinte modo: (i) background: valores $\leq$ média; (ii) anomalias de $1^{\mathrm{a}}$ ordem: valores $=$ média +1 desvio padrão; (iii) anomalias de $2^{\mathrm{a}}$ ordem: valores $=$ média +2 desvios padrão; (iv) anomalias de $3^{\text {a }}$ ordem: valores $\geq$ média +3 desvios padrão.

Pré-Processamento de cenas ASTER O sensor multiespectral ASTER (Advanced Spaceborne Thermal Emission and Reflection Radiometer), a bordo do satélite TERRA, possui três sistemas independentes, os quais coletam dados em 14 bandas espectrais: 3 bandas nas faixas do visível ao infravermelho próximo, com resolução espacial de $15 \mathrm{~m}$; 6 bandas no infravermelho de ondas curtas na resolução de $30 \mathrm{~m}$; e 5 bandas na região do infravermelho termal com resolução de $90 \mathrm{~m}$ (Abrams 2000).

As cenas ASTER foram obtidas em duas épocas distintas: setembro de 2000 (período seco) e fevereiro de 2001 (período chuvoso). O uso de imagens em períodos distintos justifica-se pela tentativa de reconhecer possíveis modificações espectrais sazonais na cobertura. Estas imagens foram adquiridas junto à NASA, já convertidas para reflectância (produto ASTER_07) (Abrams \& Hook 2002). As bandas do SWIR, originalmente com $30 \mathrm{~m}$ de resolução espacial, foram reamostradas para $15 \mathrm{~m}$, permitindo a composição de um arquivo digital único, contendo as 9 bandas do ASTER entre o VNIR e o SWIR.

Processamento digital de cenas do sensor ASTER No processamento dos dados orbitais, a principal meta foi a caracterização espectral da vegetação, particularmente a cultura de eucalipto que recobre grande parte da área de estudo, em locais com emanações naturais de gases (hidrocarbonetos), registradas primeiramente no campo por Babinsk \& Santos (inédito) e ratificadas através de dados geoquímicos.

$\mathrm{O}$ processamento digital de dados obedeceu às seguintes etapas: (i) aplicação do NDVI (Normalized Difference Vegetation Index), visando o realce de áreas com/sem vegetação; (ii) caracterização espectral da vegetação (eucaliptos) em áreas onde anomalias geoquímicas de HCs foram identificadas, em conjunto com pontos conhecidos de ocorrências de exsudações gasosas; (iii) aplicação de duas técnicas de classificação espectral, denominadas MF-MT (Matched Filtering Mixture Tuning) e SAM (Spectral Angle Mapper), objetivando separar áreas com ocorrências de exsudações de HCs, baseando-se nos seus espectros característicos.

NDVI (ÍNDICE DE VEGETAÇÃO DE DIFERENÇA NORMALIZADA) A vegetação fotossinteticamente ativa (ou 'sadia') apresenta, entre suas principais características espectrais, uma intensa absorção da radiação em comprimentos de onda do vermelho visível por pigmentos fotossintéticos (clorofila), e intensa reflexão de radiação no infravermelho próximo devido à estrutura foliar (Meneses et al. 2001) (Fig. 2). Essa propriedade foi explorada por Rouse et al. (1974) na proposição do NDVI que, desde então, passou a ser amplamente utilizado para determinação de parâmetros como biomassa, vigor, estágio de crescimento, atividade fotossintética, percentagem de cobertura vegetal e outras propriedades biofísicas da vegetação. Este índice tende a realçar as diferenças entre o mínimo de reflexão no vermelho, correspondente ao máximo de absorção por pigmentos das plantas, e o máximo de reflexão no infravermelho próximo, devido à estrutura foliar. Para o cálculo do NDVI $\left(\lambda_{\text {NIR }}-\lambda_{\text {Vermelho }} / \lambda_{\text {NIR }}+\lambda_{\text {Vermelho }}\right)$ foram utilizadas as bandas $2\left(\lambda_{\text {Vermelho }}-0,66 \mu \mathrm{m}\right)$ e $3\left(\lambda_{\text {NIR }}-0,81 \mu \mathrm{m}\right)$ do ASTER.

CARACTERIZAÇÃO ESPECTRAL DA VEGETAÇÃO AFETADA POR MICROEXSUDAÇÕES DE HCS Hipoteticamente, as principais alterações previstas para a vegetação submetida a algum tipo de estresse são apresentadas na figura 2. Embora as propriedades espectrais da vegetação na região do visível sejam alteradas, com possibilidade de amarelamento ou avermelhamento da 
planta (e.g., necroses, cloroses), o estresse também acarreta mudanças profundas das regiões do NIR e SWIR. Na região do SWIR, a reflectância tende aumentar devido as desequilíbrio hídrico foliar e, na região do NIR, a reflectância tende a diminuir em função das conseqüentes modificações na estrutura celular da planta e/ou do dossel. Considerando tais propriedades espectrais da vegetação, entre sadia e sob estresse, foram coletados espectros, a partir dos pixels da imagem ASTER ( 9 bandas VIS-SWIR), dentro e fora das áreas geoquimicamente anômalas sobre a cultura de eucalipto. A figura 5 ilustra um conjunto de perfis espectrais coletados numa área teste, dentro dessas condições de amostragem.

A análise dos espectros possibilitou a geração de uma biblioteca espectral característica de áreas com vegetação potencialmente afetada e não afetada pelos efeitos indiretos da presença de emanações gasosas. $\mathrm{O}$ espectro da vegetação afetada foi determinado a partir do estudo de espectros extraídos no centro das áreas geoquimicamente anômalas, e escolhido como mais representativo do estresse na vegetação com base nas feições de reflectância típicas previstas no modelo da figura 2. Para vegetação não afetada, foi coletado um conjunto de pixels em locais fora das anômalias e calculada a sua resposta média. (a)

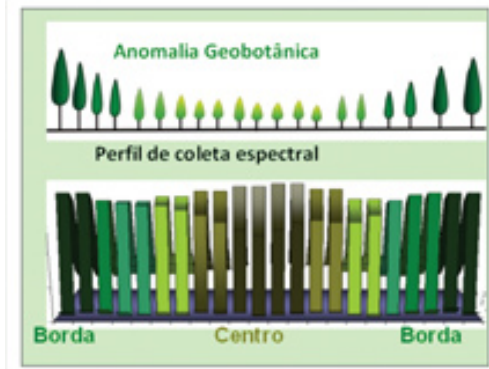

(b)

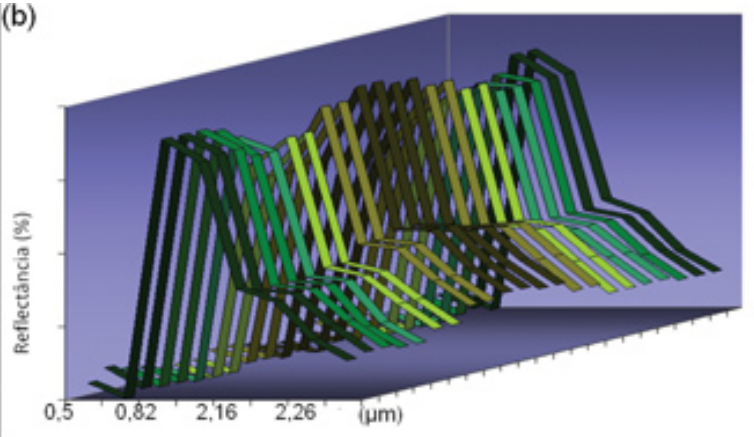

(c)

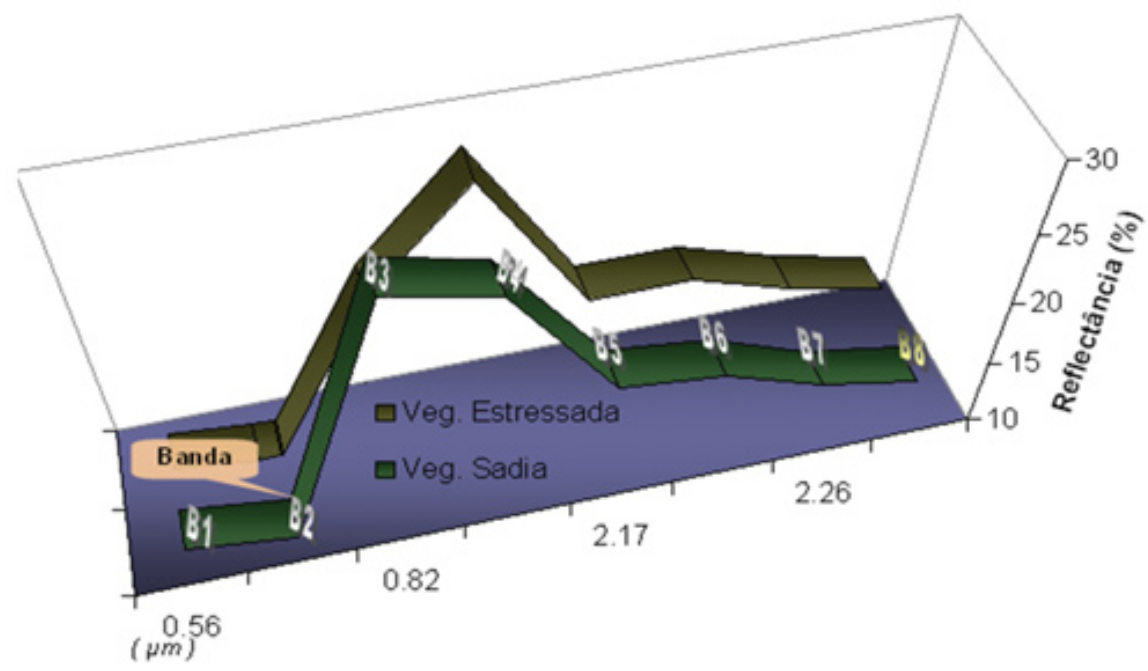

Figura 5 - Perfis espectrais extraídos da imagem ASTER (periodo seco: 05/09/2000), entre a borda e o centro de uma das anomalias geoquímicas de HCs investigadas na área de estudo. Em (A) e (B) esses perfis são apresentados, respectivamente, sem seção longitudinal e em perspectiva. Espectros verdes representam a vegetação sadia (VS), fora da anomalia geoquímica, e espectros marrons representam a vegetação estressada (VE) no centro da anomalia; outras cores representam espectros extraídos em posições intermediárias a esses dois externos. Com base nessas figuras é possível notar uma evidente e consistente variação espectral entre as zonas de borda e centro da anomalia, que é acompanhada, conforme verificado no campo, por uma variação da cobertura vegetal (A), constituindo-se, portanto, numa anomalia geobotânica bem definida. Em (C), destacam-se dois espectros extraídos no centro e na borda da anomalia geoquímica/geobotânica. Note que entre a região do NIR e SWIR (bandas B3 e B4), há uma distinta inversão espectral entre o comportamento da vegetação não afetada ou menos afetada pelas microexsudações (VS, com alta reflectância na banda $B 3$ e baixa reflectância relativa na B4) e a vegetação muito afetada pelos HCs (VE, com alta reflectância na banda $B 4$ e baixa reflectância relativa na B3). Esses comportamentos condizem com aqueles previstos para vegetações sadias e sob estresse. 
MATCHED FILTERING - MIXTURE TUNING (MFMT) A técnica MF-MT é uma desmistura espectral parcial, multi-criterial, processada em duas etapas. A primeira compreende a aplicação de um operador do tipo Matched Filter (MF). Esse filtro é capaz de realizar uma classificação espectral na escala do sub-pixel. O mesmo envolve um algoritmo que procura nos pixels da imagem as abundâncias dos espectros de referência (endmembers), utilizando-se de uma desmistura parcial através de um filtro (Matched Filter) de coincidência. Esse filtro maximiza a resposta dos espectros de endmembers conhecidos, ao mesmo tempo em que minimiza a contribuição de um background desconhecido. A reflectância em cada pixel da imagem é assumida como uma combinação linear da reflectância de cada endmember presente no pixel. Desse modo, os resultados são fortemente dependentes dos endmembers selecionados (Boardman et al. 1995). O MF gera uma imagem produto, denominada Score, cujos valores dos pixels indicam quão bem esses pixels se comparam ao endmember e qual a abundância espectral desse material de referência nos pixels. Abundância espectral num pixel corresponde à abundância física em local geograficamente redundante na superfície. O valor 'zero' nessa imagem Score indica não coincidência em relação ao endmember e ausência do material no pixel. $\mathrm{O}$ valor próximo a ' 1 ' significa uma melhor coincidência em relação ao endmember considerado, assim como uma maior abundância do material no pixel.

A segunda etapa da técnica MF-MT, denominada Mixture Tuning (MT), envolve a identificação da inverossimilhança no resultado do MF e rejeição de falsos positivos. Para cada pixel classificado pelo MF, o MT gera uma medida do grau de ajuste da coincidência entre a assinatura do pixel e do endmember. Assim, os alvos mais similares aos endmembers apresentam altos valores de Matched Filter Score e baixos valores de inverossimilhança (Boardman et al. 1995).

$\mathrm{O}$ uso do MF-MT, principalmente no que tange ao resultado do MT, requer que os dados sejam previamente normalizados, de forma que a sua média esteja centrada em 'zero' e a variância do "ruído" (ie., o que se afasta da assinatura do endmember) seja unitária. Assim, o algoritmo do MT é capaz de gerar um valor que representa a distância estatística do vetor alvo-mistura para cada pixel, o que pode ser interpretado como uma medida direta da viabilidade da mistura espectral.

SPECTRAL ANGLE MAPPER (SAM) A técnica SAM (Kruse et al. 1993, Boardman \& Kruse 1994) compreende uma classificação supervisionada n-dimensional na escala do pixel, calculada com base na similaridade entre o espectro de cada pixel na imagem e os espectros de referência (endmembers). Os espectros são tratados como vetores no espaço, com dimensionalidade igual ao número de bandas da imagem. $\mathrm{O}$ algoritmo determina a similaridade entre dois espectros através do cálculo do ângulo entre os mesmos. Diferentemente de outras técnicas, este método é insensível a mudanças de brilho e albedo na imagem, uma vez que usa o ângulo entre vetores e não os seus comprimentos.

A técnica de classificação espectral SAM é uma abordagem inicial no mapeamento de materiais espectralmente predominantes nos pixels. Todavia, superfícies naturais dificilmente são compostas por materiais espectralmente uniformes. Neste estudo, os resultados da classificação SAM foram combinados com os resultados do NDVI em um diagrama de dispersão (escatergrama), numa aproximação inédita, objetivando uma melhor avaliação e seleção dos espectros característicos da vegetação estressada. Nesse caso, o NDVI funciona como um 'ponderador' do classificador SAM, favorecendo o mapeamento de pixels na imagem que apresentam simultaneamente baixos ângulos SAM (i.e., com assinatura próxima ao espectro de referência) e valores de NDVI intermediários (i.e, distantes daqueles previstos para uma planta sadia).

Embora as formulações conceituais e matemáticas sejam francamente distintas, a ponderação dos resultados de classificação SAM pelo NDVI funciona de maneira similar à ponderação da classificação MF pelo MT.

\section{RESULTADOS E DISCUSSÕES}

Geoestatística Como resultado da avaliação estatística, mapas de concentração para cada composto foram obtidos, ou seja, mapas dos $\mathrm{C}_{1}, \mathrm{C}_{2}, \mathrm{C}_{3}, \mathrm{C}_{4}, \mathrm{C}_{5}, \mathrm{C}_{6}$, além do $\mathrm{HC}$ total. As áreas indicadas como anômalas foram sobrepostas ao mapa geológico, constatando-se sua relação espacial com contatos lito-estratigráficos e fraturas, bem como próximas ou coincidentes às drenagens controladas estruturalmente e fraturas mapeadas dentro do contexto estrutural regional (Fig. 6).

\section{Processamento Digital de Cenas ASTER}

NDVI E CARACTERIZAÇÃO ESPECTRAL DA VEGETAÇÃO A aplicação do NDVI nos dados ASTER da área de estudo permitiu realçar feições de formato circular com valores baixos de NDVI. Essas feições correspondem aos locais onde a vegetação, particularmente de eucaliptos, é menos abundante ou ausente em meio à plantação mais ampla (Fig. 7). Ao mesmo tempo, foi possível identificar áreas onde a vegetação apresentase genericamente debilitada, caracterizada por valores de NDVI intermediários, onde os eucaliptos estão com menor vigor, indicando possível estresse parcial (contornos em cor azul na Fig. 7). Oliveira (1998) sugeriu que estas feições circulares estão associadas diretamente à presença de emanações de $\mathrm{HC}$ gasosos.

A partir da caracterização espectral foi possível boa diferenciação da vegetação nas áreas geoquimicamente anômalas. A principal diferença observada foi a mudança de comportamento da reflectância nas bandas 2, 3, 4 e 6 (Fig. 8). A comparação da vegetação sadia (VS) (fora da anomalia) com a vegetação estressada (VE) (dentro da anomalia), mostrou uma inversão da reflectância nas bandas 3 e 4, com um aumento da reflectância na banda 4 para VE e banda 3 para VS, enquanto houve um decréscimo da reflectância para a banda 4 na VS e banda 3 na VE. 


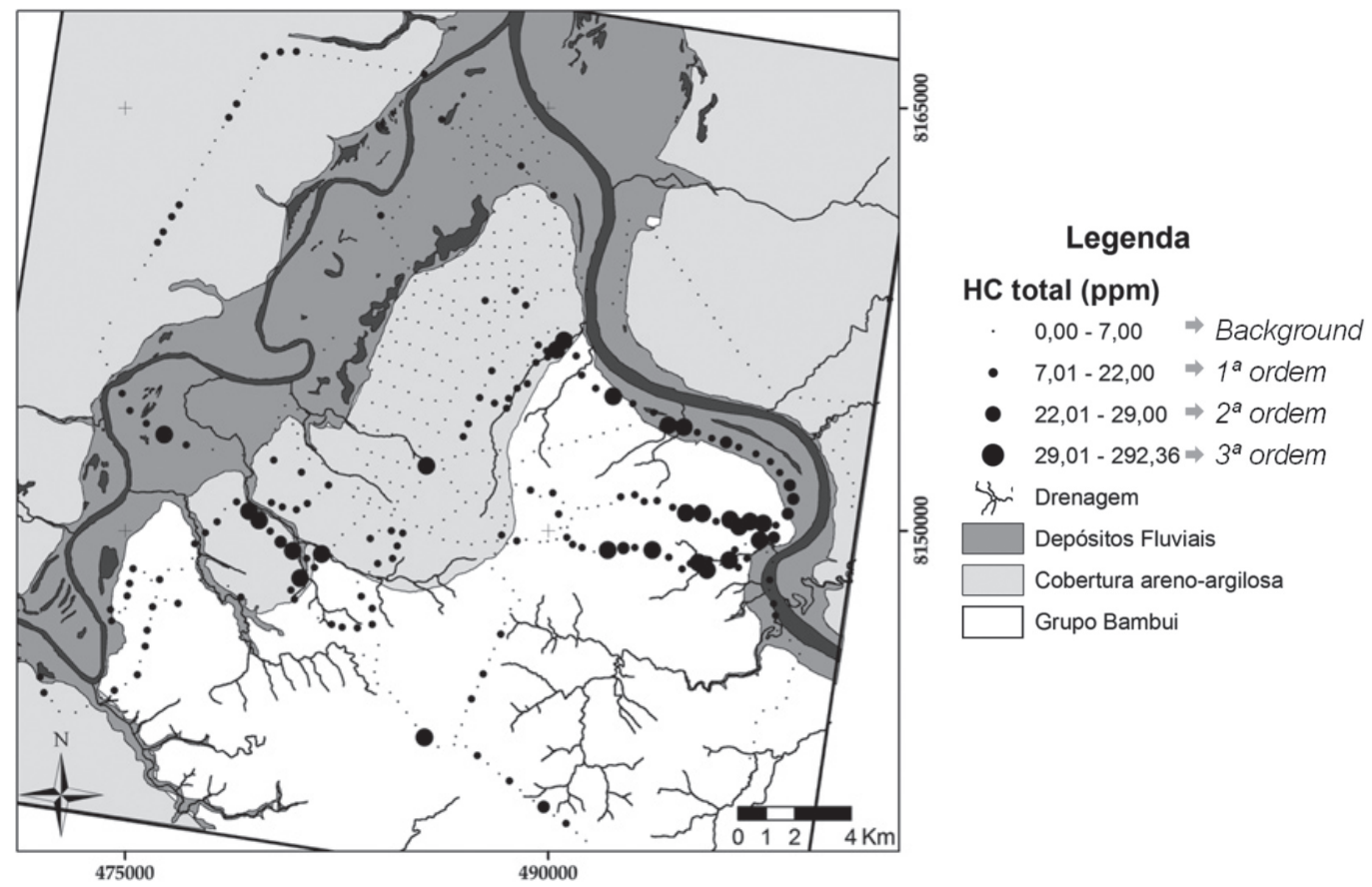

Figura 6 - Mapa geoquímico da somatória dos HCs (HC total) sobreposto ao mapa geológico.

Esta diminuição de reflectância na banda 3 (NIR) indica modificações significativas no dossel e, possivelmente, ao nível de estrutura celular das plantas, pois, nesta região do espectro, ocorre considerável espalhamento da radiação na estrutura interna nas folhas e alta reflectância. Nas bandas 4, 5 e 6 e, em geral, em todo o intervalo do SWIR, ocorreu um aumento da reflectância da VE (Fig. 8). Acredita-se que este comportamento no SWIR pode ser resultado de dois fatores: (i) da perda de água foliar somada a conseqüente modificação na estrutura celular da vegetação, devido ao estresse, resultantes da baixa fertilidade do solo; (ii) da soma das respostas espectrais da vegetação mais solos e folhas mortas, pois estas áreas anômalas têm baixa densidade de biomassa, o que favorece a exposição dos solos, que por sua vez, são geralmente recobertos parcialmente por folhas secas do próprio eucalipto.

Nas bandas 1 e 2, onde as feições espectrais da vegetação são controladas por pigmentos foliares, a vegetação sob estresse também mostrou importantes modificações na sua reflectância. A VE exibiu um significativo aumento da reflectância em relação à VS, confirmando a perda de pigmentos (clorofila) devido o estresse, resultante das deficiências nutricionais, causado indiretamente pela presença de HCs. A comparação das respostas espectrais da vegetação em imagens adquiridas no período chuvoso $(02 / 2001)$ e no período seco $(07 / 2000)$, em pontos redundantes nas imagens, mostrou que os espectros da VS e VE (Fig. 8) analisados tiveram o mesmo comportamento nos dois períodos, porém com intensidades de reflectância diferentes.

Para faixa do visível, as diferenças de reflectância entre VE e VS foram maiores no período seco, indicando que o estresse hídrico, causado indiretamente pela presença de $\mathrm{HCs}$, no período de estiagem (setembro), agrava ainda mais a perda de clorofila e a queda das folhas. Ainda no visível, comparando-se a VE nos dois períodos, percebe-se que a perda de clorofila no período chuvoso é menor. Isso implica que, em períodos mais úmidos, os efeitos do estresse na reflectância do visível são mascarados em função da manutenção ou aumento da área foliar (dossel) e vigor das folhas pela disponibilidade de água e abundante radiação solar.

No NIR (banda 3), a diferença de reflectância entre VE e VS mostrou-se expressiva (4\%). Considerando-se os dois períodos analisados, as diferenças de reflectância também foram significativas. Este comportamento indica que a vegetação de eucalipto sofreu mudanças na sua estrutura celular e, em parte, no conteúdo de água foliar, mesmo no período chuvoso. Outro fato interessante é que, apesar da reflectância na vegetação ter apresentado um aumento na banda 3 , entre o período chuvoso e período seco (implicando num ganho em estrutura, dossel), a diferença de reflectância entre VS e VE ainda foi mantida, independente da maior disponibilidade de água no ambiente.

Na região do SWIR, a vegetação tem resposta similar ao NIR, mostrando aumento de reflectância $(\sim 5 \%)$ da VE em relação à VS em toda faixa, para ambos os períodos. Isso mostra que a correlação entre aumento da reflectância e o estresse na vegetação se preserva, apesar do acréscimo hídrico no período úmido (fato que tende a provocar a diminuição da reflectância nesta faixa do espectro). Ainda no SWIR, na banda 4, a diferença da reflectância entre VE e VS no período seco é da ordem de $6 \%$ (maior diferença ao longo do espectro) e no período chuvoso aproximadamente $4 \%$, mostrando que esta diferença é a característica mais 


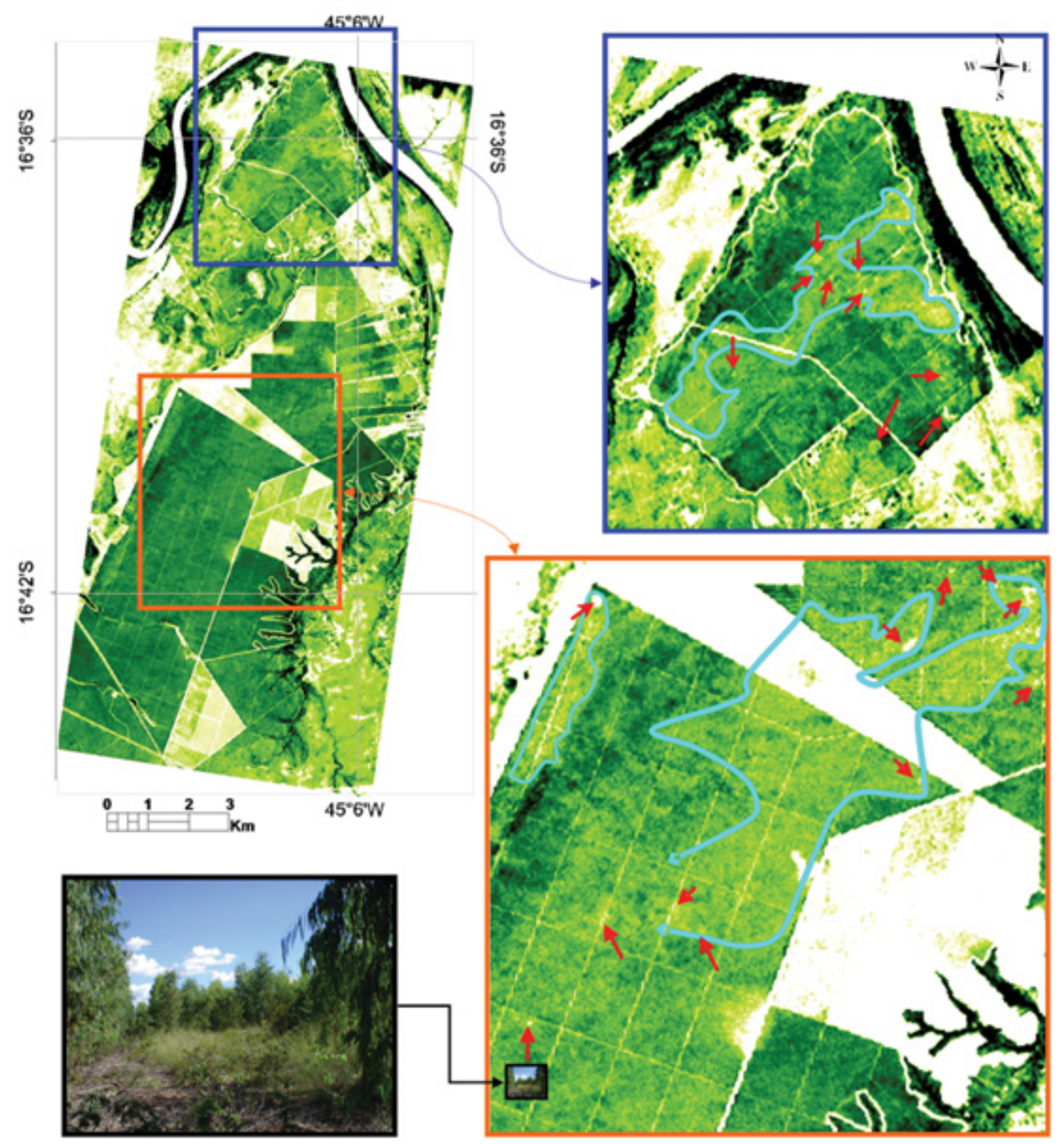

Figura 7 - Imagem NDVI, derivada dos dados ASTER adquiridos no periodo seco (05/09/2000), apresentada em pseudocor, com matiz verde. Esse produto foi preparado de forma que as matizes de verde mais claro e mais escuro, representam, respectivamente, menor e maior quantidade de biomassa. Nas duas áreas sob foco, o contorno azul marca uma ampla região onde o NDVI é mais baixo. Em maior detalhe, nota-se que nesses setores ou próximos aos mesmos, há realce de áreas aproximadamente circulares (setas vermelhas), onde os eucaliptos são pouco desenvolvidos ou ausentes. Na parte inferior da figura, é apresentada uma foto de um local verificado no campo e que valida as conclusões obtidas a partir desse produto ASTER.

marcante da VE em relação a VS, independente do período do ano (Fig. 8).

Os resultados indicam que na região do NIR e SWIR a VE apresenta um forte aumento da refletância em relação à VS, independente do período do ano (seco ou chuvoso). Na faixa do visível, entretanto, observa-se que o aumento de reflectância da VS para VE é maior durante o período de seca. Os espetros mais representativos da vegetação estressada foram identificados na imagem do período seco, onde toda faixa do espectro refletido teve importantes alterações, indicando ser esse o período mais apropriado para o mapeamento de feições espectrais na vegetação de eucaliptos sob estresses induzidos por HCs.

MAPEAMENTO ESPECTRAL As técnicas de classificação espectral MF-MT e SAM-NDVI foram aplicadas de forma localizada, objetivando mapear anomalias específicas e excluir interferências genéricas (Figs. 9a-e 10a-e). Os espectros de referência (endmembers) da vegetação estressada diagnosticados para os dois períodos (chuvoso e seco) foram usados no processo de classificação.

No caso da classificação MF-MT, os escatergramas da inverossimilhança vs valores de MF-Score vs (Figs. 9f,g e 10f,g) foram usados para a seleção dos pi- 
xels mais semelhantes aos endmembers, ou seja, pixels com valores positivos e mais altos de MF-Score e com valores baixos de inverossimilhança. Pixels com valores altos de MF-Score e altos de inverossimilhança são considerados falsos positivos e, portanto, foram descartados. Como resultado do cálculo da desmistura espectral parcial em cada pixel individual pelo MT, a soma $(\Sigma)$ dos valores de Score mostrou-se sempre menor que ' 1 '. Isso indica que praticamente todos os pixels são portadores de materiais de background não identificados com base nos endmembers considerados. Ademais, uma grande porcentagem dos pixels tem valores de MF-Score negativos ou maiores que ' 1 ', sem nenhum significado físico. Isso é também devido a operação do MF, cujo algoritmo ajusta a projeção da média dos valores de background para 'zero', fazendo com que pelo menos metade desses valores sejam negativos.

De forma geral, as áreas de ocorrência de VE mapeada pelo MF-MT são semelhantes àquelas mapeadas pelo SAM-NDVI (Figs. 9 e 10) e ambas são coincidentes ou próximas das anomalias de HCs. A maior diferença no mapeamento compreende a quan-

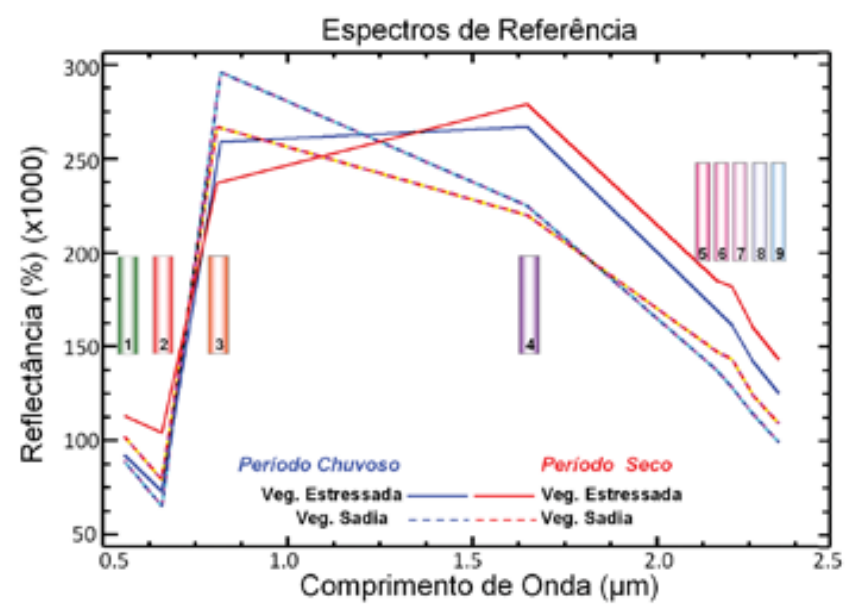

Figura 8 - Espectros de referência para áreas dentro da anomalia (vegetação estressada) e fora da anomalia de HCs (vegetação sadia), no periodo chuvoso (02-2001) e seco (09-2000), considerando o intervalo do espectro coberto pelas bandas VISSWIR (bandas 1-9) do ASTER.
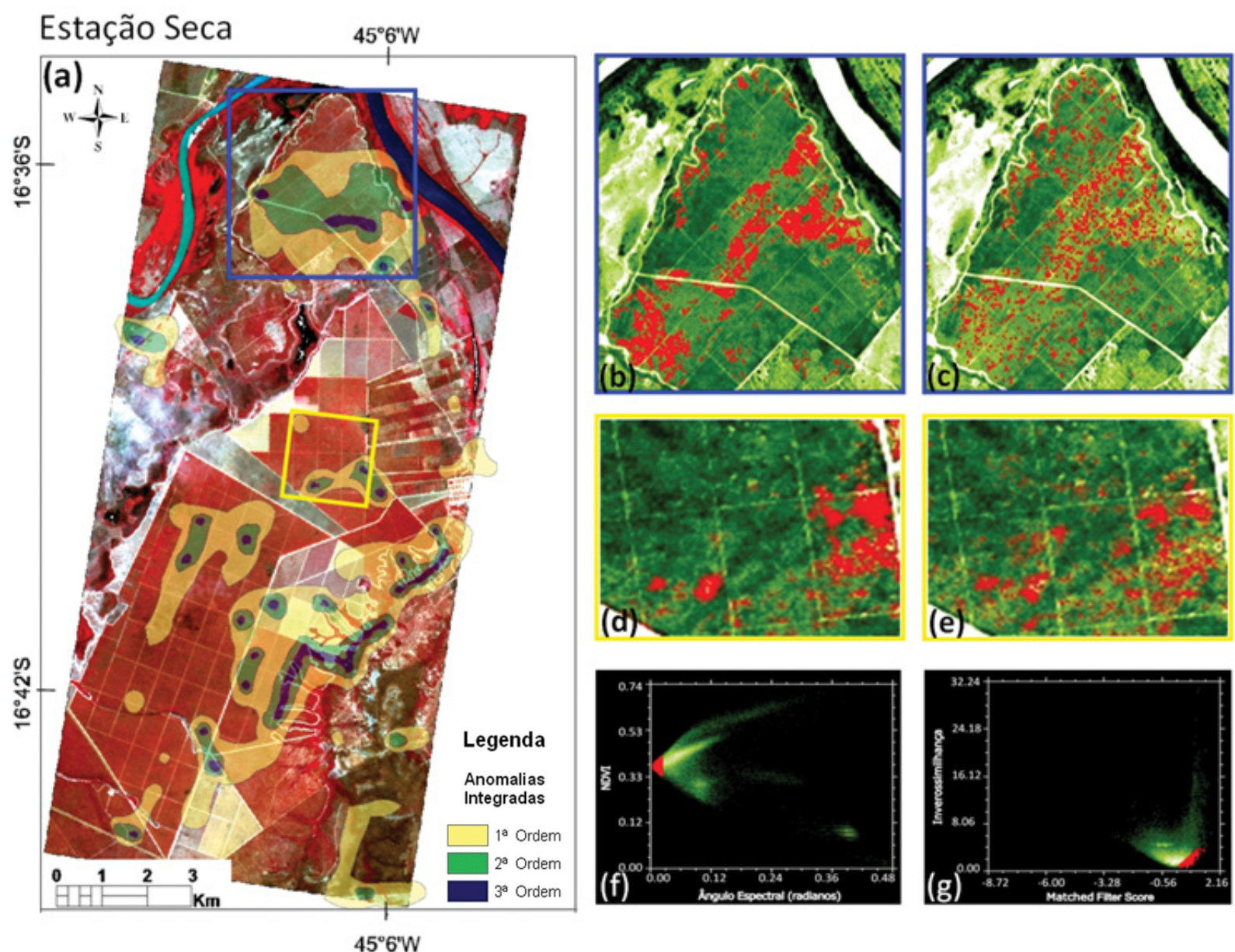

Figura 9 - Análise de dados ASTER na estação seca. (A): Imagem ASTER R3G2B1 (09/2000 - estação seca) sobreposta às anomalias geoquímicas de todos HCs integrados. (B) e (C): Resultado da classificação SAM/NDVI para vegetação estressada (VE) (em vermelho) sobreposta à imagem NDVI (fundo, em matiz verde). (D) e (E): Resultado da classificação MF-MT para VE (vermelho). $(F)$ escatergramas de NDVI vs ângulo espectral. $(G)$ inverossimilhança vs MF-Score. 

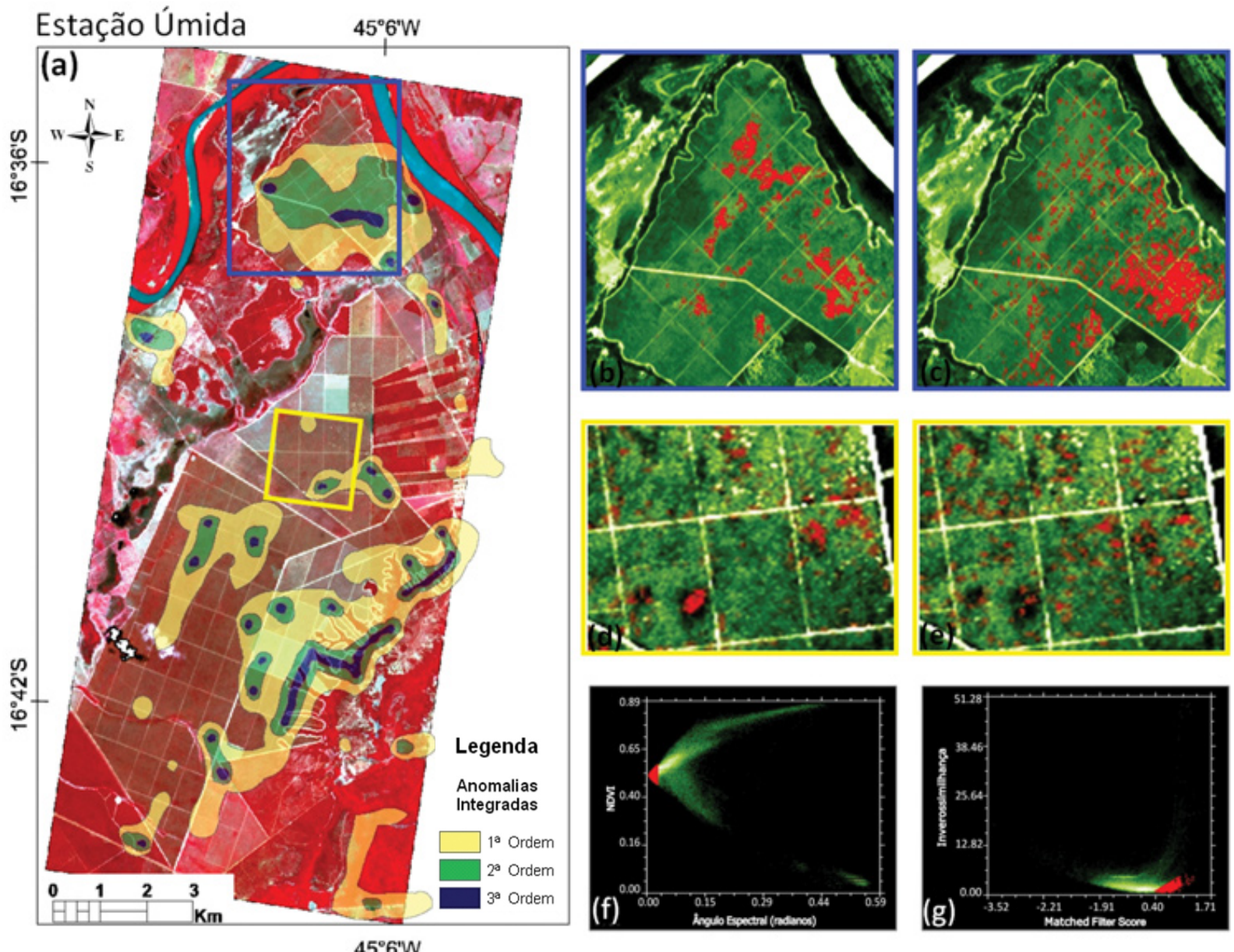

Figura 10 - Análise de dados ASTER na estação úmida. (A): Imagem ASTER R3G2B1 (02/2001 estação úmida) sobreposta às anomalias geoquímicas de todos HCs integrados. (B) e (C): Resultado da classificação SAM/NDVI para vegetação estressada (VE) (em vermelho) sobreposta à imagem do NDVI (fundo, matiz verde). (D) e (E): Resultado da classificação MF-MT para VE (vermelho). (F) escatergramas de NDVI vs ângulo espectral. $(G)$ inverossimilhança vs MF-Score.

tidade de pontos mapeados, mais restritos no caso do resultado obtido pelo MF-MT. Considerando a posição geográfica das anomalias geoquímicas (gasometria), a técnica SAM-NDVI apresentou resultados bastante satisfatórios de mapeamento baseado na geobotânica. O uso combinado SAM-NDVI permitiu o mapeamento espectral da vegetação anômala considerando simultaneamente sua assinatura (VNIR-SWIR) espectral geral (via SAM), e seu vigor e densidade (via NDVI). O mapeamento destas duas variáveis concomitantemente implica que o método é capaz de rastrear a assinatura específica da vegetação estressada (marcada por variações bruscas de gradiente entre bandas), bem como variações na reflectância relativa de espectros de mesma geometria. No caso do MF-MT, a menor quantidade de pixels mapeados como anômalos do ponto de vista geobotânico deve-se pelo menos aos seguintes fatores: (i) o método busca a assinatura específica de endmembers, o que restringe o comportamento espectral mais holístico, característico da vegetação (e.g, Almeida \& Souza Filho, 2004); (ii) o algoritmo MT diminui consideravelmente a quantidade de pixels mapeados, função da possibilidade de descarte de falsos-positivos.
Os resultados entre o mapeamento da VE nas imagens obtidas nos dois períodos analisados apresentam variações devido à recuperação diferenciada da vegetação durante o período das chuvas, e conseqüente aumento do dossel. A vegetação natural (tipo cerrado) fora da cultura de eucaliptos foi mapeada no período seco, por ambas as técnicas, como VE em pontos próximos as anomalias. Isto possivelmente ocorreu porque os espectros coletados em áreas de cerrado são semelhantes aos dos eucaliptos estressados neste período. A análise espectral de pontos no cerrado, dentro e fora das anomalias, entretanto, não forneceu informações que pudessem indicar uma concreta influência dos HCs. As mudanças espectrais observadas devemse, provavelmente, a variações devidas à presença de cerrado nativo e alterado, vegetação rasteira, mudança de solo, condições edáficas, etc. O cerrado é uma vegetação muito diversificada, complexa, de fácil adaptação e capaz de tolerar situações extremas de clima, disponibilidade hídrica e condição de solos. Ressalta-se ainda que algumas espécies de plantas que compõe o cerrado ressecam e tornam-se fotossinteticamente inativas no período de estiagem (devido ao estresse hídrico), ge- 
rando respostas espectrais muito semelhantes ao estresse oriundo indiretamente da presença de HCs.

É interessante observar que as imagens foram coletadas nos anos de 2000/2001, enquanto as análises geoquímicas de solo foram efetuadas em 1987. Exsudações são variáveis e podem migrar, se extinguir e/ou diminuir ao longo do tempo. Este tipo de variação pode ter ocorrido nos anos que se passaram entre as análises geoquímicas e a coleta das imagens de satélite. Esse fato pode explicar porque alguns locais mapeados como anômalos nas imagens não têm contrapartida nos pontos anômalos nos dados geoquímicos, e vice-versa. As variações no nível freático também podem influenciar a posição geográfica das exsudações. Considerando que os escapes são controlados por faturamento em profundidade, os HCs, quando próximos à superfície, podem sofrer influências na direção e sentido do transporte, principalmente pelas águas subterrâneas rasas (zona saturada). Essa zona sofre significativa mudança sazonal em função da recarga do aqüífero oriunda de chuvas, principalmente na profundidade do nível freático.
VALIDAÇÃO DOS RESULTADOS Grande parte das anomalias geoquímicas e VE mapeadas por sensoriamento remoto foram visitadas no campo. As clareiras detectadas remotamente foram confirmadas em sobrevôos de helicóptero, bem como em trabalhos de campo (Figs. 11a-d). Estas clareiras são de fácil reconhecimento pelo desenvolvimento incipiente ou nulo de eucaliptos e pelas dimensões das áreas afetadas, que podem variar de 3 a 150 m de diâmetro. Nas áreas anômalas, uma característica particular observada em campo foi a deficiência/ ausência da vegetação na forma de feições circulares na cultura de eucaliptos. Ademais, os eucaliptos apresentam folhas de coloração e forma diferenciadas (amareladas e atrofiadas) como reflexo das variações de clorofila, pigmentos e estrutura celular das folhas (Fig. 12a).

No campo foi possível localizar, ao longo de drenagens, escapes contínuos de gases de HCs (Figs. $12 \mathrm{~b}, \mathrm{c})$, destacados na forma de borbulhamentos na superfície da água. Esse fenômeno corrobora o controle destes escapes por estruturas (fraturas), visto que boa

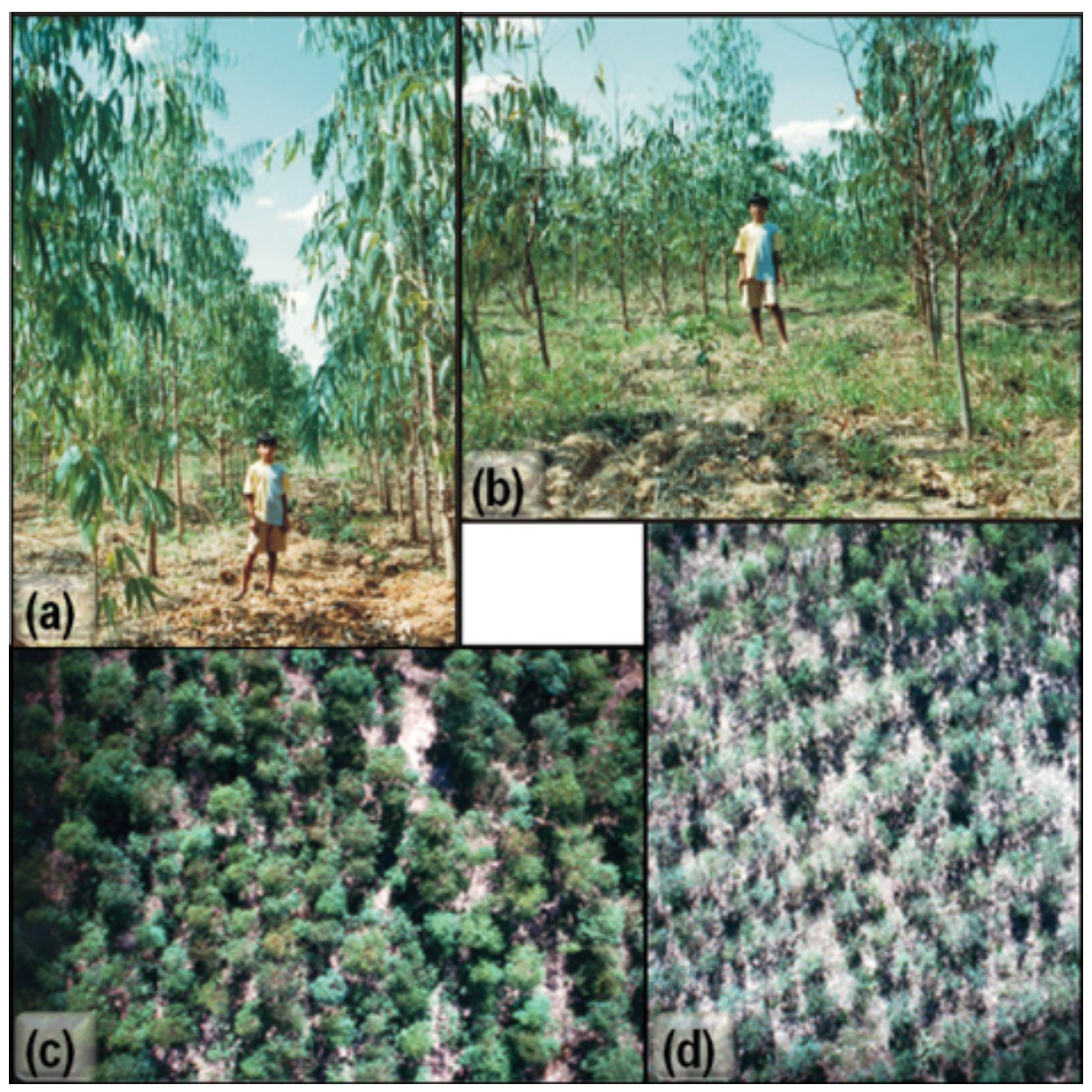

Figura 11 - Aspecto da plantação de eucaliptos de mesma geração de plantio em áreas distantes de anomalias de HCs (A) e sobre anomalias de HCs (B). Note em (A) que a vegetação é bem mais desenvolvida e homogênea, ao passo que em (B) as arvores são de menor porte, heterogêneas e há locais onde o eucalipto apresenta nanismo ou simplesmente não se desenvolveu, formando uma clareira na plantação. Esse comportamento pode ser observado mais claramente a partir de fotos aéreas (helicóptero) obtidas em porções (C) fora da área de anomalia de HC e (D) dentro de anomalia de HCs. 

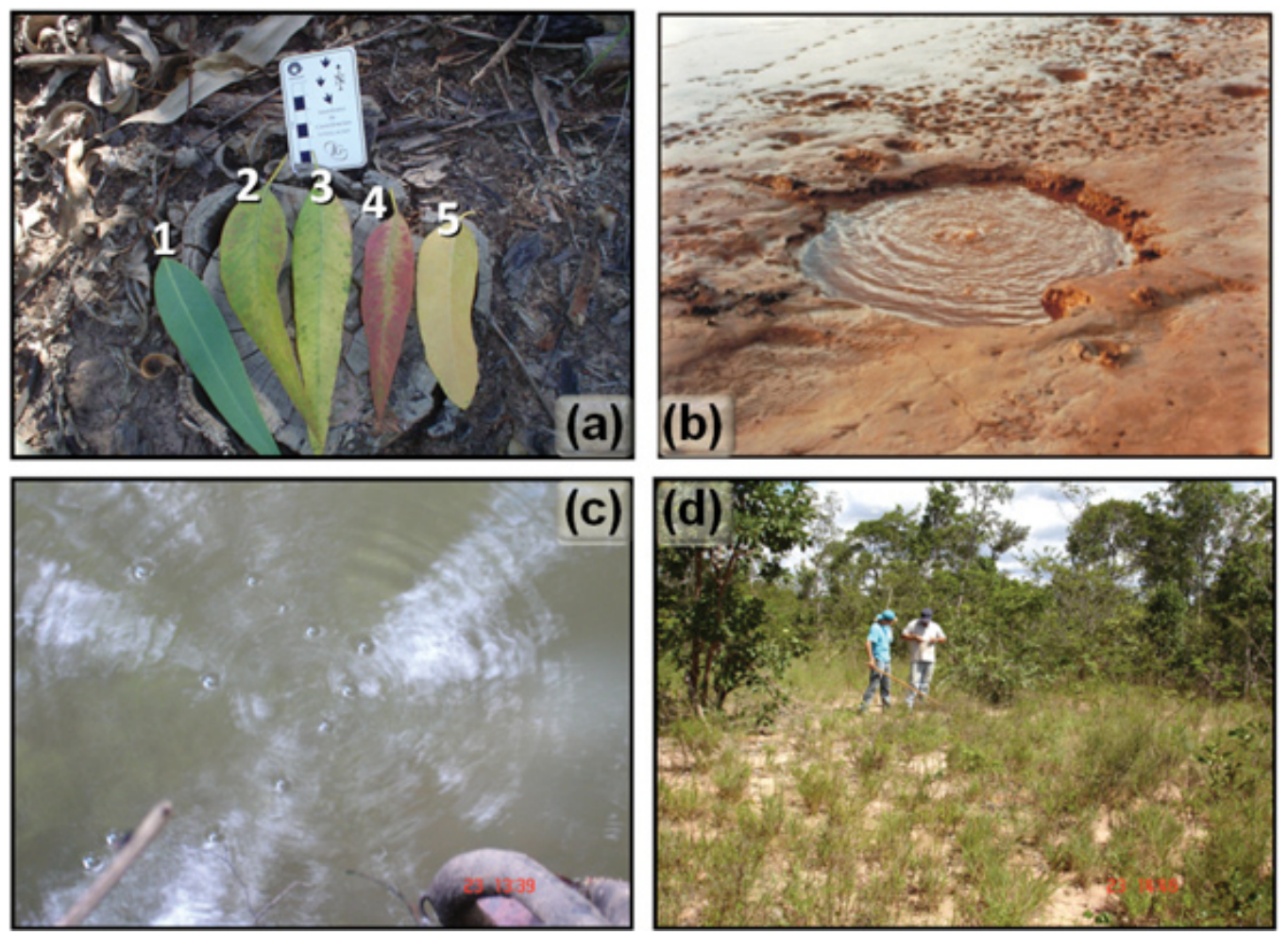

Figura 12 - Efeitos das emanações gasosas observados no campo. (A) Folhas de eucaliptos dentro e fora das anomalias - Folha sadia (1), folhas possivelmente com deficiência em cálcio e nitrogênio (2) e (3), potássio (4), e em fósforo (5). (B) Aspecto da emanação natural de gás (borbulhamentos) observada em 'mini-piscina' na margem direita do Rio Paracatu. (C) Pontos em riacho com emanação natural de gás na forma de borbulhamentos na lâmina d'água. (D) Área de cerrado em ponto com anomalias geoquímicas de $\mathrm{HC}$, onde a vegetação é pouco desenvolvida a menos densa, formado clareiras de geometria circular.

parte dos cursos d'água na região é encaixada em estruturas rúpteis. Observou-se ainda que áreas com vegetação de cerrado apresentam menor densidade nos pontos sabidamente anômalos em HCs (Fig. 12d). Todavia, não foi possível a individualização e caracterização espectral remota desta vegetação, face à variedade natural e distribuição espacial irregular de espécies no cerrado. No cerrado, foram identificadas outras espécies de plantas com problemas aparentes. Uma planta rasteira e espinhosa, popularmente denominada de "Juá", apresenta frutos e folhas subdesenvolvidas em áreas anômalas de HCs, em contraste com outras áreas.

DISCUSSÕES E CONCLUSÕES A análise do comportamento da vegetação com base em imagens ASTER convertidas para reflectância, particularmente em uma ampla plantação de eucaliptos, permitiu a caracterização de setores contendo vegetação estressada, cuja resposta espectral indicou diferentes intensidades de estresse, assim como variações sazonais. A partir desta análise ficou evidente que o período mais adequado para caracterização de alteração em vegetação de eucalipto causada pela presença de HCs no solo é a época de estiagem, pois neste período o estresse é intensificado devido, principalmente, ao déficit hídrico.

A aplicação do NDVI possibilitou a localização de anomalias espectrais circulares na plantação de eucalipto, onde a vegetação é menos densa ou ausente, ou seja, onde há presença de anomalias geobotânicas. Estas anomalias espectrais e geobotânicas são coincidentes com as áreas mapeadas por dados de gasometria, indicando sua relação com possíveis deficiências nutricionais e hídricas na vegetação, causadas pela presença de HCs. O NDVI também permitiu a definição de áreas mais amplas onde a vegetação encontra-se submetida a estresses intermediários.

O mapeamento espectral pelas técnicas SAMNDVI e MF-MT, adaptadas aos dados do sensor ASTER, foi bastante positivo nesse estudo de caso, especialmente quando aplicado localmente e englobando áreas menores. Os resultados obtidos com a técnica SAM-NDVI proporcionaram uma superior definição de áreas com vegetação estressada, quando comparados aos resultados derivados pelo MF-MT. O melhor desempenho relativo obtido pela técnica está relacionado à resposta espectral um tanto heterogênea da vegetação estressada - nesse caso, o SAM-NDVI permitiu o mapeamento espectral da vegetação anômala de forma mais holística e completa em relação as possibilidades oferecidas pelo MT-MF, que é mais restritivo.

A floresta de eucalipto, por se tratar de uma monocultura introduzida e controlada pelos fazendeiros na 
região, de certa forma facilitou a identificação das alterações impostas indiretamente pela presença de HCs. Em áreas com cerrado nativo, onde existe um número maior de espécies, muitas das quais adaptadas às condições extremas de estresse hídrico, a identificação de alterações advindas das influências de HCs mostrou-se mais complexa e requer estudos mais específicos. Ressalta-se que alguns cuidados devem ser tomados neste tipo de estudos com vegetação, pois alterações visíveis e espectrais, similares àquelas aqui descritas, podem ser causadas por outros processos (e.g., tipos de rochas, tipos de solos, clima, misturas de solos), sem nenhuma relação com microexsudações de HCs.

$\mathrm{O}$ presente trabalho apontou a associação espacial entre anomalias geoquímicas e geobotânicas na região do Remanso do Fogo - Buritizeiros (MG), com base numa aplicação de sucesso de dados ASTER, espectros modelados e técnicas de classificação espectral, somadas às técnicas tradicionais complementares. Este estudo de caso revela o potencial favorável desse ferramental para detecção e caracterização de microexsudações, as quais são indícios da ocorrência de recursos de óleo e gás em sub-superfície.

Agradecimentos Os autores agradem à Petrobras pela cessão dos dados de gasometria. C.R. Souza Filho e T. Lammoglia agradecem ao CNPq, respectivamente, pela bolsa de produtividade de pesquisa e pela bolsa de Mestrado/Doutorado.

\section{Referências}

Abrams M. 2000. The Advanced Spacebone Thermal Emission and Reflection Radiometer (ASTER); Data products for the high special resolution imager on NASA's EOSAMI platform. International Journal of Remote sensing, 21(5):847-861.

Abrams M. \& Hook S. 2002. Aster User Handbook: Advanced Spaceborne Thermal Emission and Reflection Radiometer. USA: NASA/Jet Propulsion Laboratory California Institute of Technology, v2, 135p.

Alkmim F.F., Chemale Jr. F., Endo I. 1996. A deformação das coberturas proterozóicas do Cráton do São Francisco e seu significado tectônico. Revista da Escola de Minas, 49(1):22-38.

Alkmim F.F., Brito Neves B.B., Castro Alves A.J. 1993. Arcabouço tectônico do Cráton São Francisco In: Domingues J.M.L. \& Misi A. (ed.) O Cráton São Francisco. Salvador, SBG/Núcleo BA/SE, p. 45-62.

Alkmim F.F., Martins Neto M.A. 2001. A Bacia Intracratônica do São Francisco: Arcabouço Estrutural e Cenários Evolutivos. In: Pinto C.P. \& Martins Neto M.A. (eds.) Bacia do São Francisco: Geologia e Recursos Naturais. SBG MG, Belo Horizonte, p. 9-30.

Almeida-Filho R. 2001. Processamento digital de imagens Landsat-TM na detecção de áreas de microexsudação de hidrocarbonetos, região da Serra de Tonã, Bahia. In: Simpósio Brasileiro de Sensoriamento Remoto (SBSR), Fox do Iguaçu, 10, INPE, Workshops, p. 235-242.

Almeida-Filho R., Miranda F.P., Yamakawa T., Bueno G.V., Moreira F.R., Camargo E.G., Bentz C.M. 2002. Data integration for a geologic model of hydrocarbon microseepage areas in the Tonã Plateau region, North Tucano basin, Brazil. Canada Journal of Remote Sensing, 20:2683-2688.

Almeida-Filho R., Miranda F.P., Yamakawa T. 1999. Remote detection of a tonal anomaly in an area of hydrocarbon microseepage, Tucano basin, north-eastern Brazil. International Journal of Remote Sensing, 20:2683-2688.

Almeida T.I.R. \& Souza Filho C.R. 2004. Principal Component Analysis Applied to Feature-Oriented Band Ratios of Hyperspectral Data: A Tool for Vegetation Studies. International Journal of Remote Sensing, Inglaterra,
25(22):5505-5024.

Augusto V. A., Souza Filho C. R., Almeida Filho R. 2005. Caracterização de Exsudações de Hidrocarbonetos na Bacia do São Francisco-MG Por Meio de Imagens ASTER. In: Congresso Brasileiro de Sensoriamento Remoto, 12, Goiânia, anais, p.1733-1740. CD-ROM. Disponível em: http://marte.dpi.inpe.br/col/ltid.inpe.br/ sbsr/2004/11.21.21.25/doc/1733.pdf.

Bergfeld D., Evans W.C., Howle J.F., Farrar C.D. 2006. Carbon dioxide emissions from vegetation-kill zones around the resurgent dome of Long Valley caldera, eastern California, USA. Journal of Volcanology and Geothermal Research, 152:140-156.

Boardman J.W., Kruse F.A., Green R.O. 1995. Mapping target signatures via partial unmixing of AVIRIS data. In: JPL Airborne Earth Science Workshop, 5, Summaries, JPL Publication 95-1, v. 1:23-26.

Boardman J.W. \& Kruse F.A. 1994. Automated analysis: A geologic example using AVIRIS data, north Grapevine Mountains, Nevada. In: Environmental Research Institute of Michigan, Thematic Conference on Geologic Remote Sensing, 10, Ann Arbor, Proceedings, MI, I-407 $-\mathrm{I}-418$.

Donovan T.J., Forgey R.L., Roberts A.A. 1979. Aeromagnetic detection of diagenetic magnetite over oil field. $A A P G$ Bulletin, 63:245-248.

Donovan T.J., O'Brien D.P., Bryan J.G., Cunningham K.I. 1986. Near surface magnetic indicators of buried hydrocarbons: aeromagnetic detection and separation of spurious signals. In: Thematic Conference Remote Sensing for Exploration Geology, 5, Proceedings, vol. 1, p.: 219232.

Everett J.R., Staskowski R.J., Jengo C. 2002. Remote sensing and GIS enable future exploration success: World Oil, 223(11):59-63.

Etiope G. \& Klusman R.W. 2002. Geologic emissions of methane into the atmosphere. Chemosphere, 49:779791.

Fu B., Zheng G., Ninomiya Y., Wang C., Sun G. 2007. Mapping hydrocarbon-induced mineralogical alteration in the northern Tian Shan using ASTER multispectral data. 
Terra Nova, 19:225-231.

Hoeks J. 1972. Changes in composition of soil air near leaks in natural gas mains. Soil Science, 113(1):46-54.

Huang B., Johnson J.W. \& NeSmith D.S. 1997. Responses to root-zone $\mathrm{CO}_{2}$ enrichment and hypoxia of wheat genotypes differing in waterlogging tolerance. Crop Science, 37:464-468.

Hunt J.H. 1981. Surface Geochemical Prospecting: Pro and Con. AAPG Bulletin, 65:939.

Jones V.T. \& Drozd R.J. 1983. Predictions of oil or gas potential by near-surface geochemistry. AAPG Bull., 67:932952.

Kruse F.A., Lefkoff A.B., Boardman J.B., Heidebrecht K.B., Shapiro A.T., Barloon P.J., Goetz A.F. H. 1993. The Spectral Image Processing System (SIPS) - Interactive Visualization and analysis of Imaging spectrometer Data. Remote Sensing of Environment, 44:145-163,

Kruse F.A. 2002. Combined SWIR and LWIR Mineral Mapping Using MASTER/ASTER. In: IGARSS 2002, Toronto, Canada, Also in Hardcopy, IEEE Operations Center, Pscataway,NJ, Proceedings, IV:2267-2269 (CDrom).

Lammoglia T., Souza Filho C.R., Almeida-Filho R. 2007, Caracterizacão de Microexsudações de Hidrocarbonetos na Bacia do Tucano Norte (Ba) por Geoestatística, Classificação Hiperespectral e Redes Neurais. Revista Brasileira de Geociências, 37(4):798-811

Link W.K. 1952. Significance of Oil and Gas Seeps in World Oil Exploration. A.A.P.G. Bull, 36:1505-1540.

Macek I., Pfanz H., Francetic V., Batic F. \& Vodnik D. 2005. Root respiration response to high $\mathrm{CO} 2$ concentrations in plants from natural $\mathrm{CO}_{2}$ springs. Environmental and Experimental Botany, 54:90-99.

Meneses P.R. \& Madeira Neto J.S. 2001. Sensoriamento Remoto: reflectância dos alvos naturais. Brasília, DF: UNB; Planaltina: Embrapa Cerrados, 262p.

Noomen M.F. 2007. Hyperspectral reflectance of vegetation affected by underground hydrocarbon gas seepage. Tese de Doutoramento, ITC, Enschede, the Netherlands (ITC), 167p.

Oliveira W.J. 1998. Caracterização das Emanações gasosas de hidrocarbonetos na região do Remanso do Fogo (MG) através do uso integrado de sensoriamento remoto, geoquímica, geofísica, geologia estrutural e espectrometria de reflectância. Tese de Doutoramento, Universidade Estadual de Campinas, Campinas (SP), 239p.

Pinto C.P. \& Martins-Neto M.A. (Org.) 2001. Bacia do São Francisco. Geologia e Recursos Naturais. Belo Horizonte: SBG - MG, v. Único, p. 245.

Pirone P.P. 1960. The response of shade trees to natural gas. The Garden Journal, 10:25-29.

Ripple W.J. 1986. Relationships of spectral reflectance to leaf water stress. Photogrammetric Engineering and Remote Sensing, 52(10):1669-1675.

Rouse J.W., Haas R.H., Schell J.A., Deering D.W., Harlan J.C. 1994. Monitoring the vernal advancement of retrogradation of natural vegetation. 1ed., Pasadema: JPL Publication (NASA/GSFC), $151 \mathrm{p}$.
Salisbury J.W., Walter L.S., Vergo N., D’Aria M. D. 1991. Infrared (2.1-25um) Spectra of Minerals. Baltimore, Maryland, The John Hopkins University Press, 267 p.

Saunders D.F., Burson K.R. \& Thompson C.K. 1999. Model for hydrocarbon microseepage and related near-surface alterations. A.A.P.G. Bull, 83:170-185.

Schumacher D. 1996. Hydrocarbon-induced alteration of soils and sediments, In: Schumacher D. \& Abrams M.A. (eds.) Hydrocarbon Migration and its Near Surface Expression. AAPG Memoir 66, p. 71-89.

Segel D.B. \& Merin I.S. 1989. Successful use of Landsat Thematic Mapperdata for mapping hydrocarbon microseepage-induced mineralogic alteration, Lisbon Valley, Utah. Photogrammetric Engineering and Remote Sensing, 55:1137-1145.

Smith KL, Steven M.D., Colls J.J. 2004. Use of hyperspectral derivative ratios in the red-edge region to identify plant stress responses to gas leaks. Remote Sensing of Environment, 92:207-217.

Souza Filho C.R., Tapia Calle C.H., Crosta A.P., Xavier R.P. 2003. Infrared Spectroscopy and ASTER imagery Analysis of Hydrothermal alteration Zones at the Quellaveco Porphyry-Copper deposit, Southern Peru. In: American Society for Photogrametry and Remote Sensing (ASPRS), Annual Conference, Proceedings, 1-12 (CDROM).

Thompson C.K., Saunders D.F. \& Burson K.R. 1994. Model advanced for hydrocarbon microseepage, related alterations. Oil Gas J., 14:95-99.

Toledo M.A.S. \& Zalán P.V. 1998. Reservoir Facies in the Proterozoic São Francisco Basin - Mid-Continent of Brazil. In: Int. Conference \& exhibition, AAPG, Rio de Janeiro, Extended Abstracts, p.220-221.

Trasher J., Fleet A.J., Hay S.J., Hovland M., Düppenbecker S. 1996. Understanding geology as the key to using seepage in exploration: spectrum of seepage styles. In: Schumacher D. \& Abrams M.A. (eds.) Hydrocarbon migration and its near-surface expression. AAPG Memoir 66, p. 223-241.

Van der Meer F., Van Dijk P., Van der Werf H., Yang H. 2002. Remote Sensing and Petroleum Seepage: a review and case study. Terra Nova, 14(1):1-17.

Van der Werff H. \& Lucier A. 2003. A contextual algorithm for detection of mineral alteration halos with hyperspectral remote sensing. In: De Jong S. \& Van der Meer F. (eds.) Remote sensing image analysis: including the spatial domain. Kluwer Academic Publishers, Dordrecht, the Netherlands, p. 201-210.

Yang Hong, Zhang J., Van der Meer F.D., Kroonenberg S.B. 2000. Imaging spectrometry data correlated to hydrocarbon microseepage. International Journal of Remote Sensing, 21:197-202.

Manuscrito BR 28

Submetido em 20 de dezembro de 2007 Aceito em 30 de maio de 2008 